\title{
The Role of Personality Variables in Second Language Behavior
}

\author{
By Linda L. Taylor, Alexander Z. Guiora, John C. Catford \\ and Harlan L. Lane
}

$\mathbf{T}$ EACHERS OF SECOND LANGUAGES have frequently made the observation that the ability to speak a new language authentically, to assimilate or approximate native-like pronunciation, cannot be totally accounted for by the learner's intelligence, motivation, or skill in other facets of language training. Authenticity of pronunciation can be noted early in language learning and seems not to be modified to any great extent by training or effort. ${ }^{1}$ To date there have been few research efforts specifically aimed at analyzing pronunciation skills and explaining interpersonal differences in the ability to speak authentically.

Experience and observation have prompted the suggestion that certain personality variables may play a critical role in the ability to speak a second language with native-like authenticity. Guiora has proposed that, other things being equal, the ability to speak a new language authentically is significantly related to the empathic capacity of an individual, his sensitivity to the feelings of others. ${ }^{2}$ This theory postulates that individuals who are more sensitive in their interactions with others, who are more receptive to subtle cues of behavior and feelings, would have an enhanced capacity to discern those cues and nuances which, when incorporated in speaking, produce authentic, native-like pronunciation.

A review of the literature on empathy indicates that, while theories and definitions of empathy have been well explicated, there has been little research adequately operationalizing the concept. Most definitions share the basic theory that empathy is the ability to understand the feelings of another through subtle cues of behavior or speech. Some theorists see the process as a temporary identification with another, ${ }^{3,4}$ while others propose that one reflects on his own similar feelings and experiences in order to understand the feelings of the other. ${ }^{5,6}$ The definition of empathy on which this study is based has been offered by Guiora as one of three comprehending modalities. ${ }^{7}$

The research reported herein was performed in part pursuant to Contract OEC-3-6061784-0508 with the U.S. Department of Health, Education, and Welfare, Office of Education, under provisions of P.L. 83-531, Cooperative Research and the provisions of Title VI, P.L. 85-864, as amended.

Linda L. TAYloR: Ph.D. candidate; Research Assistant, Center for Research on Language and Language Behavior, University of Michigan, Ann Arbor, Mich. Alexander Z. Guiora, PH.D.: Associate Professor of Psychology, Departments of Psychiatry and Psychology; Chief Psychologist, Neuropsychiatric Institute; Research Associate, Center for Research on Language and Language Behavior, University of Michigan, Ann Arbor, Mich. JoHN C. Catfond, Ph.D.: Professor and Chairman, Department of Linguistics; Research Associate, Center for Research on Language and Language Behavior, University of Michigan, Ann Arbor, Mich. Harlan L. Lane, Ph.D.: Professor of Psychology; Director, Center for Research on Language and Language Behavior, University of Michigan, Ann Arbor, Mich. 
Empathy is a process of comprehending in which a temporary fusion of selfobject boundaries, as in the earliest pattern of object relations, permits an immediate emotional apprehension of the affective experience of another, this sensing being used by the cognitive functions to gain understanding of the other.

In this conceptualization, empathy is one of three modes of comprehending in interpersonal relations. Inference and intuition, other modes of comprehending, operate in varying proportions with empathy to enable one to understand the behavior and feelings of others. ${ }^{2}$

An adequate measure of empathic ability, as defined above, is nonexistent. The efforts of Truax ${ }^{8}$ and Strupp" to measure the empathy of professionals in therapeutic endeavors appear to be attractive attempts at assessment but can be applied only to specific populations in circumscribed situations. The bulk of the research on empathy is based on the concept that empathy is the ability to predict what another individual will do, feel, or think in any situation suggested by the experimenter. ${ }^{10-13}$ Upon closer scrutiny, however, this ability to predict seems to be heavily dependent on additional skills such as inference, intuition and intelligence, as well as empathy. The focus on knowing the other's affective state through receptive understanding and the extension of one's attentions toward the other is minimally present. An adequate test of empathy was not found; therefore, this study provided the opportunity for developing a test of empathy for use with naive subjects in a nonclinical, laboratory setting, a chance to operationalize a clinical concept and to test it in a relatively well controlled experiment.

Research in psychotherapy by Haggard and Isaacs ${ }^{1+}$ provided an intriguing technique which seemed to lend itself to measurement of the ability to be aware of subtle cues of another's affective state, a component of empathic capacity. They have found that the showing of motion pictures of patients in psychiatric interviews at slower than normal speeds allowed observers to see facial expressions suggestive of intense feelings which were not apparent at regular speeds. Their speculation on this observation focused on the ego control of the patients. Similar speculation could be made regarding the ability of individuals to observe or perceive these cues and the relationship of this ability to empathic capacity.

Early research using motion pictures of facial expression, ${ }^{15.16}$ and photographs of faces portraying affective states ${ }^{17-20}$ provided little in the way of conclusive results and seemed understandably hampered by the methodological difficulties encountered. Subsequent investigations of problems in the labeling of affective states ${ }^{21,22}$ shed light on some of the difficulty; the correct labeling of emotions is an all but impossible task due to the differences in meaning associated with such labels and the generic rather than the specific affective states which can be differentiated. Dispensing with labeling, seemed justified in this attempt to develop a suitable technique. Another restriction of the early research on facial expression was the common goal of training all the subjects to name correctly the emotions being experienced or portrayed: the possibility of differential ability in sensitivity or empathic capacity was ignored. It is just this aspect of differential ability in perceiving and 
responding to interpersonal cues, especially in facial expression, which is crucial in explaining differences in performance.

A modification of Haggard and Isaacs' technique referred to as MicroMomentary-Expression (MME), was tested by Guiora, Lane and Bosworth in a pilot study. ${ }^{28}$ This initial attempt suggested that even in the absence of sensitive equipment for the recording of responses, a significant relationship was found between MME scores and authenticity of pronunciation by 14 teachers of French (.6 Spearman Rho). This result prompted further development of the MME as a measure of empathy and led to the following experiment.

\section{MME Empathy Measure}

A 16-mm. film of a patient in an interview situation was selected specifically for this study. Three 30 -second sequences were chosen for the measure and each was printed four consecutive times on the test film; the sound was not reporduced. The film was shown at the following four speeds for the first two sequences: 24 frames a second, $16 \mathrm{f} / \mathrm{s}, 12$ $\mathrm{f} / \mathrm{s}$, and $4 \mathrm{f} / \mathrm{s}$. These two sequences were used as practice or trial runs. The third segment was shown twice at $24 \mathrm{f} / \mathrm{s}$ to establish a measure of test-retest reliability, after which it was shown at $12 \mathrm{f} / \mathrm{s}$ and $4 \mathrm{f} / \mathrm{s}$. High test-retest reliability led to the decision to consider only the results of the second $24 \mathrm{f} / \mathrm{s}, 12 \mathrm{f} / \mathrm{s}$ and $4 \mathrm{f} / \mathrm{s}$ presentations in the data analysis.

Subjects viewing the film were instructed to indicate by pressing the button in the signal box before them each time they saw a change in the facial expression of the person in the film. The response was recorded on the timed output sheet of a 20-channel AngusEsterline chronograph, one channel of which registered cach sccond while another registered when each film segment began and ended. This record showed at approximately what time the subject indiciated the occurrence of a change. To establish a criterion for correct responses, an interval scaling technique was employed. The test segment of the film was printed out into 728 photographs, and four psychology graduate students were asked to sort the pictures on tht basis of paired comparisons into stacks, beginning a new stack when a change in expression occurred. While the style or execution of this sorting task differed markedly among the judges, there were 52 changes which all four judges agreed upon within three frames. This then became the criterion for accurate responses. Patterns of the occurrence of change frames at the various speeds were constructed and superimposed on the response records. To account for reaction time, a minor adjustment was made at the beginning of each record to establish the best fit or maximum possible correct in the initial frames. While this measure does not ask subjects to name the feeling being experienced, it does seem to be a measure of ability to attend and be receptive to interpersonal cues of affective states and thus can be considered to tap empathic capacity.

\section{Research Design}

Having constructed a tenable measure of empathy, the original hypothesis could be tested. The research design focused on both validating the empathy measure as well as establishing the relationship between empathy and authenticity of pronunciation.

The subjects in this study were all University of Michigan students: a control group of 31 primarily unpaid subjects and an experimental group of 28 paid volunteers. Approximately half of each group was male, half female. The subjects were divided into four groups ranging from 12 to 17 members each for test administration. The MME Empathy Measure, described above, and additional control measures took about two hours to administer.

In an effort to validate the MME as a measure of empathy and to delineate to what other abilities it was related, several additional measures were used. Because the MME is dependent on the visual sense at least a gross measure of visual ability seemed war- 
ranted. For this purpose a Snellen letter chart was used and the subjects were asked to read the $20 / 20$ line at 20 feet. Those with any vision disability, as indicated by this procedure, compensated by correcting their distance from the movie screen. Deviations from normal were rare. Subjects were urged to perform under optimal conditions, thus people wearing glasses were instructed to keep them on.

The MME Empathy Measure, as theoretically formulated, is morc than a mcasure of perceptual ability. To test this it was necessary to control for the ability to see random movements in a complex pattern other than a human face. No suitable measures were available, su a technique similar to the MME was constructed. This measure referred to as the Pattern Perception Test consisted of three 30-second sequences of a film showing the changes in the pattern of a cathode ray spectroscope visually presenting the tonal patterns of individual musical instruments. ${ }^{24}$ The speed of the film was constant for this task $(24 \mathrm{f} / \mathrm{s})$, and again the first two segments served as trial runs and the responses of the third segment, recorded on the chronograph output record, were the test data. The audio component of the film, which the subjects did not hear, provided a criterion for correct responses to the instructions, "Indicate when a change appears in the pattern." It was anticipated that perceiving changes in facial expression involved more than simply the ability to perceive changes in a complex pattern.

In addition to the above controls, a relevant measure of empathy was needed to provide a way to validate the MME Empathy Measure. For this purpose the first research reported on empathy served as the most suitable criterion. ${ }^{25}$ This study analyzed stories told to Thematic Apperception Test cards in terms of the subject's ability or tendency to describe the feelings of the characters in the stories. The richness of the description of feelings was regarded as a measure of empathy. While obviously a crude measure, it seemed nevertheless the most appropriate for a naive population. The subjects were shown four TAT cards ( $7 \mathrm{GF} ; 7 \mathrm{BM} ; 9 \mathrm{GF} ; 6 \mathrm{BM}$ ) for five minutes each on the movie screen and were given standard instructions to write stories about the pictures. Two clinical psychology graduate students experienced in diagnostic testing served as judges. They rated the description of each character in each story on a five point scale. They reread and judged the stories according to the degree of psychological mindedness; complexity of plot, motivation, levels of awareness, interpersonal relationships. ${ }^{26}$ The criterion of psychological mindedness was used to determine whether the responses or the MME Empathy Measure reflected empathy, or merely a sophistication about and perceptivity to psychological factors. Records of the Verbal and Mathematical Ability scores on the Scholastic Achievement Test were available for nearly all subjects.

The week following the administration of the above test battery, 28 of the subjects, by prearranged assignment, attended four one-hour sessions on consecutive days in which they were taught basic dialogues and sentence patterns in Japanese by a native speaker. On the fifth day they were tested as follows. The subject engaged in a dialogue with the teacher, using five specific sentences learned during the training period. Then the teacher spoke five sentences in Japanese and the subject was asked to repeat each one after the teacher. The first five sentences will be referred to as Spontaneous $(\mathrm{Sp})$ and the last five as Repetitions ( $R p)$. All the tests were taped, and two native Japanese linguists and the teacher served as judges. They rated each sentence on a five-point rating scale for General Authenticity ( $\mathrm{ga}_{\mathrm{a}}$. Important phonetic elements such as accent patterns or the pronunciation of certain sounds were delineated for each sentence and these Specific Criteria (sc) were rated on a three-point scale in a second presentation of the tests. Sentences were replayed until the judges had rated each of the criteria. While this approach at structuring the subjective rating procedure is not unique (MLA Proficiency Tests), its construction was specific to the material presented in this experiment and has provided an important differentiation in language ability. None of the test subjects had had any previous training in Japanese or any other Fastern language.

\section{Results}

The MME scores were tabulated in a number of different ways. The most 
significant were the following: (1) MME total score: total number of responses at each speed; (2) MME accurate: number accurate according to "best fit" method at each speed, (3) Residual MME: multiple regression analysis on acuurate responses and total responses in Pattern Perception test, to control for style and perceptual ability; (4) MME efficiency: ratio of accurate responses to total responses at each speed; and (5) MME criterion or Beta score: Determined by probability of false alarm, indicates subject's criterion for rejecting true negatives and accepting false positives in $\mathrm{z}$ score terms.

All those MME scores dependent on the absolute number of responses made (total number of responses, number of accurate responses, and residual scores) correlated negatively with the four language authenticity scores, significantly so with Spontaneous (Specific Criteria). The proportion of accurate scores, termed a measure of efficiency, reverses this relationship and shows a strong positive correlation with Spontaneous (Specific Criteria).

Regarding each film segment as a series of one-second trials provided a means for scoring not only accurate responses but correct rejections, similar to techniques employed in signal detection research. ${ }^{27}$ The probability of the subject's reporting a false alarm, indicating that a change occurred when the accuracy criterion does not coincide, provides the Criterion or Beta score. The Criterion score indicates when the subjects will decide to report a change and while it is a component of style, it is not unrelated to perceptual ability and sensitivity. The Criterion score correlated positively with the Spontaneous (Specific Criteria) score, significant at the .05 level.

Using the Pattern Perception Test data as a correction for perceptual ability and response style did little to control for the predominating problems in response style. The Criterion score seemed to provide the most definitive correction for response style by providing an index of careful or cautious decision making. The MME Empathy Measure was most highly related to the Pattern Perception Test.

The validity of the MME Empathy Measure was to be estabilshed by its relationship to a crude measure of sensitivity to the feelings of others, i.e., the TAT Empathy Measure. As Table 1 indicates, this was not accomplished, and the relationship between MME and TAT Sensitivity to feelings is not significant.

The language authenticity scores were most highly related to the Scholastic Aptitude Test-Verbal Ability Score. This variable was related to all four language measures, significant at the .01 level.

The relationship of the language scores to the TAT measure of Sensitivity to Feelings and the measure of Psychological Mindedness seems to put the findings into an interesting perspective. The Spontaneous (Specific Criteria) score is significantly (.05 level) related to the TAT Sensitivity to Feelings measure, while the TAT measure of Psychological Mindedness is significantly related to the measure of Repetitions (General Authenticity).

This pattern focuses on the emergence of two clusters of independent variables and their significant relationship to two different pronunication skills (dependent variables). As Table 2 indicates, there are four variables that significantly relate to Spontaneous (Specific Criteria) and are relatively inde- 
Table 1.-Summary of Correlations of Language Scores

\begin{tabular}{|c|c|c|c|c|c|c|c|c|}
\hline & $\mathrm{f} / \mathrm{s}$ & Sp(ga) & $\mathrm{Rp}(\mathrm{ga})$ & $\mathrm{Sp}(\mathrm{scc})$ & $\operatorname{Rp}(s c)$ & Pat.P. & $\begin{array}{l}\text { 'IAT' } \\
\text { Senst. }\end{array}$ & $\begin{array}{l}\text { Interjudge } \\
\text { Reliability }\end{array}$ \\
\hline MME Total & 21 & -.08 & -.10 & $-.50+$ & -.15 & $+.46^{\circ}$ & -.13 & \\
\hline \multirow[t]{2}{*}{ Responses } & 12 & --.05 & --.20 & $--.48+$ & -.12 & & -.07 & \\
\hline & 4 & -.19 & -.26 & $-.60+$ & -.20 & & -.20 & \\
\hline MME Accurate & 24 & -.07 & -.06 & $-.47 *$ & -.12 & $1-.35$ & & \\
\hline \multirow[t]{2}{*}{ Responses } & 12 & -.08 & -.09 & $-.50 \dagger$ & -.12 & & & \\
\hline & 4 & -.27 & $-.42^{\circ}$ & -.55 & -.23 & & & \\
\hline MME Residual & 24 & $\cdots \cdot 13$ & .10 & $-.42^{\star}$ & .22 & & & \\
\hline Combined 24,12 & $\& 4$ & -.26 & -.28 & $-.32 *$ & -.24 & & & \\
\hline MME Proportion & 24 & +.10 & +.01 & +.30 & +.15 & & & \\
\hline Acc. (Efficiency) & 12 & $\begin{array}{r}+.07 \\
+10\end{array}$ & $\begin{array}{r}-.04 \\
+06\end{array}$ & $\begin{array}{l}+.35 \\
+35\end{array}$ & $\begin{array}{r}+.08 \\
+05\end{array}$ & & & \\
\hline \multirow{2}{*}{$\begin{array}{l}\text { MME Criterion } \\
\text { or Beta }\end{array}$} & 12 & $\begin{array}{r}+.10 \\
+.04\end{array}$ & $\begin{array}{l}\top .00 \\
-.05\end{array}$ & $\begin{array}{l}+.03 \\
+.40\end{array}$ & $\begin{array}{r}+.03 \\
+.12\end{array}$ & & +.06 & \\
\hline & 4 & +.11 & +.15 & +.30 & -.17 & & --.10 & \\
\hline \multicolumn{2}{|l|}{ Pattern Perception } & +.17 & +.20 & +.15 & +.09 & & & \\
\hline \multicolumn{2}{|l|}{ SAT-VA +} & +.47 & $+.63 \uparrow$ & $+.48 \uparrow$ & $+.63 \dagger$ & & -.08 & \\
\hline \multicolumn{2}{|l|}{$\begin{array}{l}\text { TAT-Sensitivity } \\
\text { TAT-P }\end{array}$} & +.14 & +.09 & +.38 & +.28 & & & $+.78+$ \\
\hline \multicolumn{9}{|l|}{ TAT-Psych. } \\
\hline Mindedness & & +.30 & $+.38^{\circ}$ & -.02 & +.15 & & +.15 & $+.67+$ \\
\hline \multicolumn{9}{|l|}{ Interjudge } \\
\hline Reliability & & $+.89+$ & $+.88+$ & $+.77 \dagger$ & $+.71 \dagger$ & & & \\
\hline
\end{tabular}

pendent of each other. When combined in a multiple regression formula, this cluster predicts more than half the variance of the Spontaneous (Specific Criteria) language scores.

A different combination of three independent variables, again relatively unrelated, accounts for more than half the variance of the Repetition (General Authenticity) language scores.

Table 2.-Intercorrelations of Spontaneous (Specific Criteria)

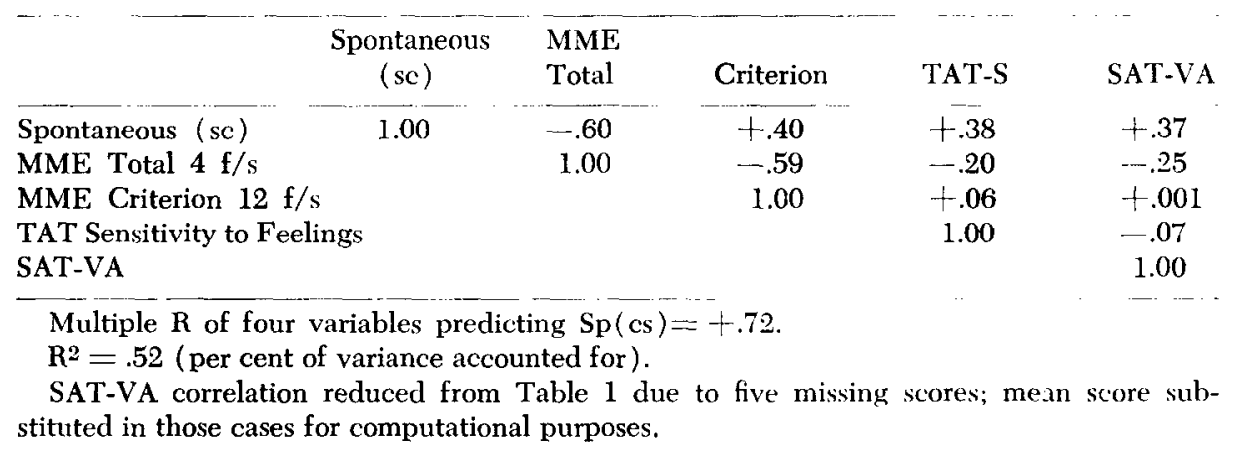


Table 3.-Intercorrelations of Repetitions (General Authenticity)

\begin{tabular}{lcccc}
\hline & $\begin{array}{c}\text { Repetition } \\
\text { (ga) }\end{array}$ & MME Total & TAT-Psych. & SAT-VA \\
\hline Repetition (ga) & 1.00 & -.26 & +.38 & +.59 \\
MME Total 4 f/s & & 1.00 & +.31 & -.25 \\
TAT-Psychological Mindedness & & & 1.00 & +.06 \\
SAT-VA & & & & 1.00
\end{tabular}

Multiple $\mathrm{R}$ of three variables predicting $\mathrm{Rp}(\mathrm{ga})=+.72$.

$\mathrm{R}^{2}=.52$ (per cent of variance accounted for).

SAT-VA correlation reduced from Table 1 due to five missing scores; mean score substituted in those cases for computational purposes.

\section{Discussion}

In interpreting the results presented above, the first issue must be to deal with the validity of the MME test as a measure of empathy. Since the TAT measure of sensitivity to feelings is the only other available measure of empathy, it is the standard for comparison. While the strength and sensitivity of the TAT-Sensitivity of Feelings measure is certainly questionable, the absence of a strong positive relationship between this method of expressing awareness of the feeling of others, which has at least as much face validity as the MME, and the test of awareness of emotions through changes in facial expression suggests that other behaviors were also being expressed in MME responses.

The MME scores based on the absolute number of responses, which all correlate negatively with language authenticity scores, may be the result of anxiety about the task or the intensity of the feelings observed. The number of total MME responses may be the channeling of this anxiety into random and uncertain behavior. This possibility seems to be supported by the negative relationship, though not significant, between the MME total scores and the TAT measure of empathy, referred to above. This indicates that the MME scores based on absolute number of responses do not measure what is theoretically defined as sensitivity to affective cues.

The total MME scores relate positively and to a level of significance only with the Pattern Perception Test scores. This may indicate that the MME is merely a noisy measure of perceptual ability, or, since the two tests are structurally alike and similarly ambiguous, a measure of the ability of an individual to tolerate anxiety and anticipation (a higher number of responses reflects lower tolerance).

The fact that the Pattern Perception Test is not negatively related to the language scores, as is the MME, suggests that the content of the MME test, the expression of human emotion, elicits a response style not explained by perceptual ability alone. The most likely alternate explanation is that anxiety is aroused by the emotions displayed as well as by the ambiguity of the task.

The pattern of relationships between the MME scores reflecting total number of responses and Spontaneous (Specific Criteria) and the criterion or Beta score on the MME and Spontaneous (Specific Criteria) may be 
interpreted as follows. People who are aware of the detailed nuances in a second language and incorporate them respond less frequently than other subjects on the MME and tend to make fewer mistakes or false alarms when they do respond. This ability to attend to details without jumping into action or responding prematurely seems to be another aspect of empathic ability distinct from the ability to tolerate anxiety. Both are a key factor in understanding the MME results.

It has to be concluded that the MME Empathy Measure is not a direct measure of empathy per se but measures facets of response to tasks demanding empathic understanding. It is a significant predictor of the inability to perceive subtle cues due to disruptive anxiety in perceiving emotions. The MME criterion or Beta score gives additional information regarding response to feelings and seems to show that a careful, cautious style allows one to respond accurately to the feelings of the other.

The two TAT measures employed (crude measures of empathy and psychological mindedness as they are) also provide significant predictors of the language behavior under study. The significant (.05 level) correlation found between TAT Sensitivity to Feelings and Spontaneous (Specific Criteria) suggests that people who are more aware of feelings are more sensitive to the details and specific aspects of the second language and reflect this in speaking. A translation of this finding into personality dynamics would suggest that these people tend to extend themselves toward others to understand their feelings, appreciate the details of their behavior and respond appropriately.

The significant relationship between Psychological Mindedness and Repetition (General Authenticity), significant at the .05 level, indicates that those who see interprersonal behavior in terms of motivations and expectations can sound as though they are speaking a second language authentically, but on closer analysis have either not heard or not incorporated the correct details. The psychologically minded have a need to understand underlying factors and causality in interpersonal relationships which reflects a more egocentric need to be perceptive to and master of situations. This is reflected in their ability to master the general impression of authenticity in speaking the second language, but it is devoid of the sensitivity to details which makes it really accurate. The performance of subjects scoring high on General Authenticity was characterized by fluency and a sense of self-confidence which those who scored high on Specific Criteria but lower on General Authenticity lacked. This style of comprehending the total picture and imposing order from one's own framework rather than by extending oneself to perceive the feelings and behaviors of the other is different from empathic understanding and is more similar to the intuitive mode of comprehending as defined by Guiora., ${ }^{72}$

Intuition is a mode of comprehending in which external cues normally inadequate for logical judgment and/or prediction give rise to apparently direct, immediate and accurate judgment and/or prediction through the mediation of idiosyncratic associations organized according to allological principles.

In intuitive comprehending the listener gains understanding by spontaneous and unconscious reflections on his own experiences and feelings and in this 
case on his own verbal repertoire. While a valid and useful skill, its focus is the opposite of empathy, self-directed rather than extended toward the other.

The correlations between the intuitive measure and the ability to sound authentic when mimicking sentences, and the unrelated empathic measure and the ability to reproduce correctly the subtle details of the second language spontaneously points out important differential abilities in language pronunciation. This may explain the ability of most actors to imitate dialects when speculation as to their character is that they are more likely to be egocentric than empathic.

While comprehensive reviews of linguistic research indicate that conventional measures of intelligence are inconsistent and unreliable in predicting success in language learning, ${ }^{29,30}$ it has been suggested that certain aspects of intelligence may come to light through "closer analysis of the criterion of performance". ${ }^{31}$ The research design presented here has followed through on this speculation and added confirmation to existing findings that verbal intelligence, as differentiated from mathematical components of intelligence, is significantly related to authenticity of pronunciation. The high correlation between language pronunciation and SAT-VA found here confirms the finding in the pilot study. ${ }^{23}$ Verbal intelligence accounts for the greatest measured variance in authentic pronunciation (41\% in the pilot study, 22 to $40 \%$ of the variance in this study). It is likely that it is the interplay of verbal intelligence with other catalytic factors that explains its relevant role in this and the pilot study. As the definition of empathy above postulates, intelligence is the cognitive mediating force necessary for comprehending to occur and be accurate, though it is not part of empathy itself.

These independent variables described above fall into two clusters representing the dimensions of empathy and intuition referred to earlier. The cluster of variables predicting more than half the variance of the ability to pronounce correctly specific details of the new language represents a dimension of emp pathy. This empathy dimension is composed of two necessary adjunctive skills and two essentially empathic skills. The first two, the ability to tolerate anxiety aroused by observing the expression of emotions and intelligence as a mediating cognitive factor, are based on the MME total score at $4 \mathrm{f} / \mathrm{s}$ and SAT-VA respectively. These characteristics are essential for empathic understanding to operate successfully. The two empathy variables are the ability to be involved in feelings, as measured by the TAT-Sensitivity to Feelings, and the ability to attend to and identify emotional expressions, as measured by the Criterion score of the MME at $12 \mathrm{f} / \mathrm{s}$. The emergence of two variables, unrelated, capturing different aspects of empathic capacity leads to the speculation that empathy consists of several components and may best be understood and measured by identifying the various skills necessary, which together or in various combination, allow for empathic understanding to occur. The relationship between this empathy dimension and the Spontaneous (Specific Criteria) skill confirms the original hypothesis that the ability to speak a second language with native-like pronunciation is related to empathic ability $(\mathrm{R}=+.72)$.

Another grouping of independent variables allows for the prediction of 
more than half the variance of the ability to sound generally authentic when repeating sentences in the new language. The group of predictors comprise a dimension of intuition. The ability to tolerate anxiety (MME total at $4 \mathrm{f} / \mathrm{s}$ ) and intelligence (SAT-VA) are again necessary adjuncts for intuition to occur. In this dimension, anxiety over emotional expression is a much less debilitating factor than it is in the empathic dimension. This is consistent with the dynamic descriptions of the two skills. Anxiety disrupts the essential focus of attention to the other which is necessary in empathy and is less disruptive when the understanding is based on self-directed reflection. Intelligence plays a similar role here as a necessary ingredient for appropriate processing and mediation. The variable of TAT-Psychological Mindedness, described above as a component of intuition, is the key factor in defining this constellation and its relationship to Repetition (General Authenticity). The confident, fluent repetition of the second language phrases reflect not detailed attention but a need to master the situation by producing similar sounds from a more familiar verbal repertoire. Again, this constellation of intuition-related components becomes an important predictor of general authenticity in repeating sentences in the new language.

Recent findings indicate that people differ not only in preference but in ability with regard to sensory modalities. ${ }^{32,33}$ They may differ in whether they prefer to hear or see the material presented and may show a measurable difference in their sensitivity to perception in these sensory modalities. This is an important consideration in planning future research to explore further the results presented above. The design of the study presented here presupposes equal ability in visual, audio, and lingual abilities. The subject's empathy was measured by intricate visual stimuli while the teaching was entirely spoken and the criterion was in the form of verbal utterances. If people do differ in ability across modalities, the existence of more consistent and significant results might have been attenuated because of crossing the modalitics in this research design. To eliminate the problem in future research, an empathy measure might be constructed in the auditory dimension. A possiblility would be to blur the distinct words in portions of speech typifying emotional states, leaving only the supra-segmental aspects such as pitch, rhythm, and volume and ask subjects which of a list of emotions or emotional dimensions is being experienced in each example.

\section{Conclusions}

While the specific aim of constructing a unique and direct method of measuring empathy was not achieved, important and significant relationships between authenticity of pronunciation of a second language and constellations of factors representing the personality variables of empathy and intuition have been found, confirming the hypothesis under investigation and the underlying psychological theory. It has been shown that personality characteristics interacting with the interpersonal situation of language learning result in differences in language performance, specifically in the authenticity of pronunciation.

Two constellations of variables representing independent modes of com- 
prehending were identified and each was a significant predictor of a skill in second language pronunciation. The empathy dimension consisted of a measure of tolerance to anxiety cause by affective stimuli, intelligence necessary for cognitive understanding, a cautious style of responding only to affective cues of the other, and the ability to be involved in emotional experiences. The first two, anxiety and intelligence, are adjuncts to empathic functioning, while the last two, attention to an involvement in emotional expression, are independent components of empathic capacity. The empathy dimension is significantly related to the ability to learn and recall exact details in the pronunciation of a second language, accounting for more than half the variance of this skill.

A second mode of comprehending was defined by three unrelated variables and represents the intuitive dimension. Anxiety as a distractor and intelligence as a facilatator are again necessary parts of this dimension, the prime factor of which is the component of understanding the motives and complexities of interpersonal situations and gaining mastery through self-directed reflection. This dimension of intuition is significantly related to the ability to sound fluent and authentic in repeating sentences, accounting for more than half the variance of this skill, but not to the exact pronunciation of precise details predicted by the empathy dimension. Intuition is more closely related to narcissism than is empathy, as stated by Guiora, and this may account for two common observations regarding facility in second-language pronunciation : fluency in pronunication often seems to reflect self-confidence and a degree of narcissism, and the ability to mimick well seems void of empathic understanding.

\section{ACKNOWLEDGMENTS}

The authors gratefully acknowledge the methodological advice so generously given by Dr. Warren T. Nonnan, Dr. Richard W. Pew, and Mr. Neil Kalter, all of the Department of Psychology, University of Michigan. Mrs. Suzuko Osawa Nishihara, of the Far Eastern Language Department, University of Michigan, gave invaluable assistance in planning and teaching the language classes and in constructing the Specific Criteria for testing.

\section{REFERENCES}

1. Carroll, J. D., Clark, J. L., Edwards, T. M., and Handrick, F. A.: The foreign language attainments of language majors in the senior year: A servey conducted in U.S. Colleges and Universities. Final report for contract OE-4-14-048 with the U.S. Office of Education, Department of Health, Education, and Welfare, 1967.

2. Guiora, A. Z.: Toward a systematic study of empathy. Comp. Psychiat. 8:375$387,1967$.

3. Fliess, R.: The metapsychology of the analyst. Psychoanal. Quart. 11:211-227, 1942.

4. Stewart, D.: The psychogenesis of empathy. Psychoanal. Rev. 41:216-228, 1954.

5. Schafer, R.: Generative empathy in the treatment situation. Psychoanal. Quart. 28:342-373.

6. Kohut, H.: Introspection, empathy and psychoanalysis. Amer. Psychoanal. Ass. J. 7:459-483, 1959.

7. Guiora, A. Z.: On clinical diagnosis and prediction. Psychol. Rep. 17:779-784, 1965.

8. Truax, C.: Effective ingredients in psychotherapy: an approach to unraveling the patient-therapist interaction. J. Counsult. Psychol. 10, 256-268, 1963.

9. Strupp, H.: Psychotherapists in Action. New York, Grune \& Stratton, 1960.

10. Dymond, R. A.: A scale for the measurement of empathic ability. J. Consult. Psychol. 13:127-133, 1949.

11. Baker, B., and Block, J.: Accuracy of 
interpersonal prediction as a function of judge and object characteristics. J. Abnorm. Soc. Psychol. 54:37, 1957.

12. Speal, S.: The relationship of phenomenological empathy to certain personality and interpersonal variables. Dissert. Abstr. 60:2734, 1960.

13. Sternberg, D.: The growth of empathy: an investigation of the relationship between sensitivity to the self-perception of others as a function of frequency of interpersonal contact and certain selected personality variables. Dissert. Abstr. 62:3290, 1962.

14. Haggard, L. A., and Isaacs, R. S.: Micromomentary facial expressions as indicators of ego mechanisms in psychotherapy. In Gottschalk, L. A., and Auerbach, A. H. (Eds.): Methods of Research in Psychotherapy. New York, Appleton-CenturyCrofts, 1966.

15. Carney, L.: Studies of emotional reactions. J. Exp. Psych. 7:325-341, 1924.

16. Mandel, S.: The differentiation of emtional responses in infants. J. Comp. Psychol. $7: 265,1927$.

17. Ruckmick, C. A.: A preliminary study of the emotions. Psychol. Monogr. 39:30-35, 1921 .

18. Frois-Whittmann, J.: The judgment of facial expression. J. Exp. Psychol. 13:113. $151,1930$.

19. Feleky, A.: The expression of the emotions. Psychol. Rev. 21:33-41, 1914.

20. Guilford, J. P.: An experiment in learning to read facial expression. J. Abnorm. Psychol. 24:191-202, 129-130.

21. Scholsberg, H.: Three dimensions of emotion. Psychol. Rev. 61:81-88, 1954.

22. Osgood, C. E.: Dimensionality of the semantic space for communication via facial expression. Scand. J. Psychol, 7:1-30, 1966.

23. Guiora, A. Z., Lane, H. L., and Bosworth, L. A.: An exploration of some personality variables in authentic pronunciation of a second language. In Lane, H. L., and Zale E. M. (Eds.): Studies in Language and Language Behavior Progress Report IV. Ann Arbor, Mich., Center for Research on Language and Language Behavior, 1967.

24. Bell Telephone Laboratory: Action Pictures of sound: A Portrayal of Dynamic Spectra. Pattern Display by Cathod Ray Sound Spectroscope. Film Produced by the Transmission Department of Bell Telephone Laboratory, 1947.

25. Dymond, R. A.: A preliminary investigation of the relation of insight and empathy. J. Consult. Psychol. 12:228-233, 1948.

26. Holt, R, R., and Luborsky, L.: Personality patterns of psychiatrists. Menninger Clinic Monograph Series, No. 13. Topeka, Kans., The Menninger Foundation, 1958.

27. Swets, J. A.: Signal Detection and Recognition by Human Observers. New York, Wiley, 1964.

28. Guiora, A. Z., Bolin, R., Dutton, C., and Meer, R.: Intuition, a preliminary statement. Psychiat. Quart. [Suppl.] 39:110-122, 1965.

29. Gardner, R. C., and Lambert, W. E.: Language aptitude, intelligence, and second language achievement. J. Educ. Psychol. 56:191-199, 1965.

30. Carroll, J. B.: The prediction of success in intensive foregin language training. In Glaser, R. (Ed.): Training Research and Education. New York, Wiley,1965

31. - : Research on teaching foreign languages. In Gage, N. L.(Ed.): Handbook of Research on Teaching. Chicago, Rand McNally, 1963.

32. Pimsleur, P., Sundland, D., and McIntyre, R.: Under-achievement in foreign language learning. Final report, U.S. Department of Health, Education and Welfare, Office of Education, Washington, D.C., 1963.

33. Moore, R.: Language and intelligence: A longitudinal study of the first eight years. Hum. Develop. 10:88-106, 1967, and $11: 1-24,1968$. 